the inside of the bole through it being, as shown in fig. 4, turued out concave, in the latter rather larger than the edges, somewhat like the rim of a spectacle frame; then the internal circle $M$, being accurately fitted into it, is swelled or bulged out by means of a taper mandrell, driven into the hole in its centre to such a size that it will fill the outer ring or circle exactly, in the manner of fig. 4, and then it cannot get out of its place sideways, because the interior circle exactly fills the groove or hollow parts formed round within side the annular saw $K$ : this internal circle $\mathbf{M}$ thus becomes the axis on which the saw turns. The circumference of the saw, as shown in fig. 5, is notched all round with fine teeth, which perform the cutting, and at intervals it is cut with deep notches, into which the pins on the face of the wheel $c$ are received, and act upon the ring so as to turn it round: the interior ring $M$, or axis of the saw, is supported by being screwed to a piece of iron, $\mathbf{N}$, which also carries the centre pin of the wheel $d$, and is itself screwed to the inside of the brass plates FG of the frame, by the screws show $n$ in $f g .1 . W$ is a handle to guide and direct the saw, moving it upon its several joints $\overrightarrow{\mathrm{B}}$ and $\mathrm{E}$ into any required position; 0 is a spring which in certain positions balances the weight of the frame $F G$, \&c. depending upon the joint $\mathrm{B}: \mathrm{P}, \mathrm{fig} .2$, is a gauge consisting of a flat slip of iron, PS, which is fitted to the underside of the frame; it has a grouve formed in it through which a screw passes, and the nut $Q$ will fasten it at any required point; it is moved sideways by the screw $R$, and adjusted to advance to any required distance towards the extreme end of the saw : its use is to regulate the depth to which the saw shall penetrate in cutting.

The very singular property of this annular or circular saw, in cuting deeper than its centre, renders it likely to prove of great utility in a variety of surgical and mechanical operations.

LXV. On the Changes of Colour produced by Heat in coloured Bodics. By M. GaY-LussaC*.

$\prod_{\text {He various colours presented by the different bodies of }}$ nature prescnt variations in their shades, and frequently pass from one tint to another when they are exposed to $a^{\prime}$ certain tenperature. There would be nothing remarkable in these changes, if they were owing to a chemical altera-

* Amalcs de Chimi, Iuguat 1812, No. 2:8, p. 171. 
tion; but I shall only regard those here, which, being subordinate to the intensity of heat, cease to take place immediately when the temperature resumes its primitive state. I shall divide this memoir into two parts: the first will contain a detail of facts, and the second their relations with other phænomena.

\section{First Part.}

I ought to premise, that in the following experiments I have not taken an exact account of the temperature to which the coloured bodies have been expnscd. I generally contented myself with heating pleces of porcelain upon burning coals, and afterwards thro ing coloured buties upon them: sometimes however I exposed them unon an earthen plate at the heat of the sand-bath, but never lower than $300^{\circ}$, cr higher than $400^{\circ}$. Lest I should juaccurately define the various changes of colour produced by heat, 1 requested M. Merimée, who is well versed in the colour business, to be present at my experiments, and to write down the results with his own hand. I cannot do better, therefore, than faithfully republssh the notes which he took upon that occasion.

\section{Experiment 1.-Chinese Fimilion.}

Its colour is not a pure red: it contains yellow. On exposing it to the heat of the sand-bath it became deeper, and assumed the carmine shade.

Experiment 2.- Oxide of Mercury obtained ly the Calcination of the Nitrate of Mercury.

Its colour is orange. At the temperature of $100^{\circ}$ it assumed a deepish red, and approached the colour of common cinnabar: at a stronger heat it became of a fine cinnabar red, and at a still stronger heit about $300^{\circ}$ it passed to the violet colour, first assuming a blue cojour. The colour of this oxide beng orange renders it capable of passing to a brilliant red, but not to a fine violet*.

\section{Experiment 3.-Red Lead.}

It presents nearly the same phænomena with the oxide of mercury ; but, as its orange colour is finer, beat makes it assume a more brilliant red. The violet colour which is developed in it afterwards is not finer than that of the oxide of mercury.

- Whet we pound this oxide of mercury, it takes an olive yellow shade cos, han is pinitue rolour, and which is developed the better, the :ru.did. This new colour gets deeper when heated, $\therefore$ inun colour. 
Experiment 4.-Nitrate of Cobalt slightly dried.

This salt, which when cold is of a wine red, becomes blue the instant its temperature is a little raised: when cooled it resumes its primitive colour, and thus passes successively from one tint to another, when we vary its temperature, independently of the influence of humidity.

Experiment 5.-Red Sulphuret of Arsenic, or Realgar.

When in the mass it is red : but when it is pounded it has an orange colour mixed with a chesnut red. On exposing it to heat, it takes the colour of colcothar.

Experiment 6.-Glass of Antimony.

It presents when pounded an orange yellow colour clouded with a good deal of gray. At a beat of about $400^{\circ}$ it assumes a brownish red, as if it had been mixed with the red oxide of iron.

Experiment 7.-Oxide of Bismuth prepared by decomposing the Nitrate of Bismuth by Heat.

Its colour is a dirty white mixed with a little orange yellow. On gradually raising its temperature, it becomes of a very fine yellow, and passes progressively to the chesnut red : upon cooling it resumes its primitive colour. We ought to remark, that it does not pass by the pure orange: thus the red cint which it acquires is not a pure rerl, but that of the rust of iron.

Experiment 8.-Oxide of Tin prepared with Nitric Acid, and calcined.

Its colour is similar to flowers of sulphur sullied by a little gray. When heated it assumes a yellower shade with a little red.

Experiment 9.-Oxide of Zinc.

Upon calciring nitrate of zinc exempt from iron, an oxide was obtained which when cold is of a straw colour: a heat of about $300^{\circ}$ gives it a colour like that of Naples yellow. At a higher temperature the shade is yellower, and compared with that of the chromate of lead is greener, and more intense.

\section{Experiment 10.-Flowers of Sulphur.}

The first stage of heat produced a more lively yellow, in which we remarked the gray tint which accompanies this colour. When they began to fuse, the shade became olive yellow, and the colour increasing it became red.

Experiment 11.-Yellow Sulphuret of Arsenic, or Orpiment.

We may regard this colour as the purest which mineral substances 
substances can furnish. When exposed to heat it is at first orange, and afterwards takes the red colour of the oxide of iron.

\section{Experiment 12.-Turbith Mineral.}

Its colour is of a very fine yellow resembling the ranumculus; when heated it becomes of a brick-red colour.

\section{Experiment 13.-Chromate of Lead.}

When cold, it is of a very fine yellow mixed with a litile orange. Upon heating it, it pasees to the orange, but does not become so brilliant as might be expected.

Experiment 14.-Muiate of Iron at the Maximum.

Its natural colour when it is concentrated is of a fine yellow, but, when applied in a thin layer its culour is that of bionm flowers a little sullied. On raising llic temperature it assumes a chesnut colour. Red therefore has been added to its primitive colour.

\section{Experiment 15.-Green Oxide of Chrome.}

When projected upon a piece of cartien ware almost red hot, it becomes of an olve colour, as if we had mixid a little colcothar with this oxude.

\section{Experiment 16.-Liquid Muriate of Copper.}

This salt was of a greenish biue similar to what is called water-green. When heated, but not so as to evdporate 11 water, it becomes of a hoe creen, as it it had beets male brighter with gambogs: when cold it resumes lis prmmive colour. If we concentrate it more it retains, when co!d, a fine green colour, containing however less yllow than when it is wann. On evanoring it again, it becontes of a dirty ochrey yellow. We may obtain the colour by mining a little onange colour with the fine green colnur which it had formerly.

Experiment 17.-Highly concentrated Nitrate of Copper.

When cold it is of a pure blue, and does not appear to contain any green. When beated it becumes of a blueish green, as if a little gamboge had heen added to the solution.

$$
\text { Experiment 18.-Azure. }
$$

When exposed to a heat of $400^{\circ}$ it is altered to gray, as if a little orange colour bad been added to it.

$$
\text { Experiment 19.-Protoxide of Copper. }
$$

When cold it has a grayish tint mised wuh brownish red, which makes a dirty violer with gray. With heat it Vol.41. No. 182. June 1813. E e becomes 
becomes gray like charcoal powder: in this way it assumed a blueish shade.

\section{Experiment 20.-Deutoxide of Copper.}

Its colour is a deep gray containing a little brownish red. On exposing it to heat, it becomes blacker, which proves that it has taken from the blue which has neutralized the red and the yellow.

\section{Experiment 21.-Deutoxide of Iron.}

It is of a gray colour, retaining very little of the brownish red. Heat produces blue, and its colour becomes of a purer gray, which by opposition makes the former appear redder.

\section{Experiment 22.-Peroxide of Antimony; Pearl Powder of Kerkringius.}

Its colour is a bright white, like white lead. When heated it takes a slight shade of dirty yellow or yellowish gray. We obtain a similar effect with the volatile oxide of antimony, but in a feebler degree.

LXVI. Researches upon the Heat developed in Combustion, and in the Condensation of Vapours. Read before the French Institute on the 24th of Felruary and 30th of November 1812. By Count Rum ford, F.R.S. Foreign Associate of the Imperial Institute of France, $\mathcal{E}^{\circ} \mathrm{C} . \mathbb{Q}^{\circ} \mathrm{c}$.

[Continued from page 297.]

\section{$\S$ V. Heat developed in the Combustion of Spirit of Wine and Alcohol.}

As the constituent parts of these inflammable liquids may be regarded as well determined, by the results of $M$. de Saussure's excellent work, I undertook a second time to examine them, with a view to what were the quantities of the heat which are developed during their combustion. I had begun this business five years ago; but after having made a considerable number of experiments, I abandoned it on account of the great difficulties which I met with; but the instant I found means to make my apparatus more perfect I recommenced.

Before giving the details of my experiments, I ought to say a few words upon the difficulties which attended the enterprise, even since I possessed my new apparatus, and upon the means $I$ used to surmount them. There were even dangers to which I was exposed, which it is necessary 